Dossier: La escritura en los desplazamientos: viajes, expediciones y naufragios

\title{
Entre las dos orillas del drama El teatro como viaje y arma en la conquista europea de las Américas
}

Omar Guadarrama Aguirre

Estudiante de la Maestría en Artes (Estudios InterAmericanos)

Universidad de Bielefeld, Alemania

omarguadag@gmail.com

http://orcid.org/0000-0002-2661-4903

Recibido: 14 de febrero de 2020

Aceptado: 30 de marzo de 2020

Resumen: Los procesos de conquista que se han dado a lo largo de la historia de la humanidad se han valido de diversos tipos de armas (espadas, pólvora, tanques, bombas atómicas, etc.) para alcanzar sus objetivos. Sin embargo, la conquista española fue un tanto diferente ya que utilizó en conjunto con las armas tradicionales, una arma muy poco común: el teatro.

Las manifestaciones artísticas siempre se han destacado por "fusionarse" en etapas que se consideran "zonas híbridas" como lo señala Robert Richard. En este sentido, tanto las influencias y corrientes europeas e indígenas han presentado el mismo suceso, no sólo a partir del siglo XVI sino durante un proceso permanente se puede vincular y considerar cómo es que el teatro fue una herramienta fundamental para el desarrollo de una parte de la conformación de lo que hoy conocemos como las Américas, una región llena de transiciones.

En el caso específico de México, la conquista europea produjo diversos movimientos a partir del fenómeno teatral que sirvió a los españoles como un vehículo de transmisión de ideas, conceptos, valores e inclusive religión. El teatro

\section{(๑) $\Theta \odot$}

La Revista Estudios es editada por la Universidad de Costa Rica y se distribuye bajo una Licencia Creative Commons Atribución-NoComercial-CompartirIgual 3.0 Costa Rica. Para más información envíe un mensaje a 
Dossier: La escritura en los desplazamientos: viajes, expediciones y naufragios

entendido como re-presentación(es) de la(s) realidad(es) entre Europa y las Américas.

Palabras clave: Conquista española; Teatro performance; Identidad artística; Cultura indígena, Cultura europea; Travesías literarias; Identidad y drama.

\title{
Between the two sides of the drama: theatre as a journey and weapon in the European conquest of the Americas
}

\begin{abstract}
The processes of conquest that have taken place throughout the history of humanity have used various types of weapons (swords, gunpowder, tanks, atomic bombs, etc.) to achieve their objectives. However, the Spanish conquest was somewhat different as it used, in conjunction with traditional weapons, a very rare weapon: the theatre.

Artistic manifestations have always stood out for "merging" in stages that are considered "hybrid zones" as Robert Richard points out. In this sense, both European and indigenous influences and currents have presented the same event, not only from the sixteenth century but during a permanent process can be linked and consider how the theater was a fundamental tool for the development of a part of the shaping of what we know today as the Americas, a region full of transitions.

In the specific case of Mexico, the European conquest produced diverse movements based on the theatrical phenomenon that served the Spanish as a vehicle for the transmission of ideas, concepts, values and even religion. The theatre understood as a re-presentation(s) of the reality(s) between Europe and the Americas.
\end{abstract}

Keywords: Spanish conquest; Performance theatre; Artistic alterity; Indigenous culture; European culture; Literary journeys; Identity and drama.

\section{(c) (i) (-)}

La Revista Estudios es editada por la Universidad de Costa Rica y se distribuye bajo una Licencia Creative Commons Atribución-NoComercial-CompartirIgual 3.0 Costa Rica. Para más información envíe un mensaje a 
Dossier: La escritura en los desplazamientos: viajes, expediciones y naufragios

Comienzo esta ponencia con una cita que, personalmente, engloba parte del inicio de este viaje que he comenzado sobre el tema o posible puerto de llegada pretendido.

La primera cita es un fragmento tomado de la obra teatral que nos regalará el escritor Carlos Fuentes (1970, p. 96) que dice:

CIHUACÓATL: Señor: dos mundos sin contacto ni comparación se han encontrado. Ni nuestros dioses son los de ellos, ni los de ellos son los nuestros; no hay ideas comunes en esta contienda, y al no haberlas, sólo habrá eso: contienda. Prepárate para ella.

MOCTEZUMA: (reaccionando con energía) La comedia ha terminado, sacerdote.

CIHUACÓATL: (Inclinándose) La tragedia apenas empieza, señor.

Sin los naufragios, Europa y las Américas no se hubieran conocido, o no de la forma en la que lo hicieron, así como la historia y la literatura nos lo han contado. A partir de su encuentro comenzamos a respirar otras tierras, otras islas, otras formas de ver las realidades vinculadas a través de un solo mar llamado la lengua española.

Los diarios llenos de viajes y palabras guardan secretos y realidades que sorprenden a quien los observa, a quien los palpa, a quien los huele. Ese ha sido un espacio temporal, imaginario y escrito de los viajantes de la palabra desde el punto de inicio hasta al de llegada.

Aunque en medio de cada travesía se producía una interacción dentro del cosmos. Palabra mágica y poderosa utilizada por nuestro personaje anfitrión y aventurero, Alexander von Humboldt. Quien en una de sus primeras declaraciones escritas al llegar a Venezuela comentó su sentir y sorpresa por las tierras que pisaba luego del viaje a través de unas palabras que escribió a su hermano Wilhelm:

"Corríamos como locos de aquí para allá, sin poder hacer claras observaciones porque al coger algún ejemplar raro lo dejábamos cuando veíamos que a su lado había otro todavía más curioso" (Humboldt, 1779, p. 284).

\section{(c) (i) (-)}

La Revista Estudios es editada por la Universidad de Costa Rica y se distribuye bajo una Licencia Creative Commons Atribución-NoComercial-CompartirIgual 3.0 Costa Rica. Para más información envíe un mensaje a 
Dossier: La escritura en los desplazamientos: viajes, expediciones y naufragios

Existen diversas hipótesis e investigaciones sobre el cómo los españoles conquistaron y colonizaron las tierras americanas desde su llegada (e inclusive hasta el día de hoy) a través de su viaje a nuestro continente. De qué modos y estrategias se valieron para inculcar parte de su historia, tradiciones (como la religión católica) y, sobre todo, el idioma que hasta la fecha es considerado (por algunos) un baluarte de nuestra "identidad".

Años más tarde, luego de la travesía del botánico y aventurero alemán. Llegaron los españoles a tierras americanas a través de un viaje. En su prólogo de la obra Todos los gatos son pardos, se puede leer lo que escribió Carlos Fuentes (1970: 15) al respecto del tema sobre los naufragios: "Hernán Cortés, al desembarcar en México el día previsto por los augurios divinos, cumplió la promesa destruyéndola. México impuso a Cortés la máscara de Quetzalcóatl. Cortés la rechazó e impuso a México la máscara de Cristo".

Como sabemos, la rapidez de los cambios culturales e institucionales es vertiginosa, y así mismo ha sido la transmisión de nuestra lengua española. Enseñado este idioma al iniciarse la Conquista nos convenció de que actúa en nombre de Dios y que cumple la voluntad divina pero luego se cambió esa actitud.

Esos hombres que llegaron eran, en su mayoría, "soldados" de Cristo, luego se convirtieron en gobernadores, después capitanes generales, algunos más en jueces y hasta reyes. El indio (o indígena), teóricamente vasallo libre, trabajaba para el señor, para el cura doctrinario, para el cacique o para la misión a la que con el paso del tiempo fuera adscrito.

¿Cómo es que aprendimos a hablar este idioma que nos comunica y nos hace construir realidades a través de cada una de las palabras que pronunciamos? ¿Y cómo es que, al mismo tiempo, utilizamos el propio idioma para cuestionar parte de nuestra "original" o "impuesta" identidad?

Conceptos vinculados a la alteridad se han mezclado a partir de una incomunicación entre las culturas que los unen. Lo local con lo que nos ofrecieron. Se vive en un inconsciente gesto de negación de lo local y de la identidad diversa, propia, que no es sino mezcla e influencia de nuestro pasado en colisión (indígena y colonial). Pero no somos una u otra cosa, somos el resultado, la hibridación, la mezcla, una tercera cosa en beligerancia consigo misma.

\section{(c) (i) (-)}

La Revista Estudios es editada por la Universidad de Costa Rica y se distribuye bajo una Licencia Creative Commons Atribución-NoComercial-CompartirIgual 3.0 Costa Rica. Para más información envíe un mensaje a 
Dossier: La escritura en los desplazamientos: viajes, expediciones y naufragios

Con esto, me gustaría recordar hoy un poco el pasado que nos persigue. Los procesos de conquista que se han dado a lo largo de la historia de la humanidad se han valido de diversos tipos de armas (como son espadas, pólvora, pistolas, etc.) para alcanzar sus objetivos. Sin embargo, la conquista española fue un tanto diferente ya que utilizó, en conjunto con las armas tradicionales ya mencionadas y toda la violencia que éstas desarrollaron, una arma muy poco común: el teatro.

Y es aquí donde ofrezco y les comparto este posible inicio, una especie de pretensión, de viaje, un impulso, una energía, o tal vez un simple sueño, que me ha llevado a desear vincular algunos conceptos artísticos y culturales que ha ofrecido el teatro en el estudio, análisis y posibles respuestas a nuestra constitución como seres mezclados, hombres y mujeres a los que nos han llamado "los mestizos", "los criollos" así como a la manera en que este hecho violento-escénico ayudó a la adherencia del idioma español a nuestras vidas.

Las palabras de San Ignacio de Loyola de por qué se recurría al teatro para la instrucción (en este caso la evangelización) las describe Jerry M. Williams (1993, p. 54):

1) Se requería menos concentración y esfuerzos particulares por parte de los frailes y, 2) Este método instructivo le ganaba la atención a los indios. [...] Con mucha más emoción de lo que pudieron oír y medio componer en los sermones sobre el dogma del pecado original o de las postrimerías del hombre.

Son varias las acciones que se realizaron por parte de los que llegaron hacia los que habitaban. Aquellos que pertenecían a su lugar y a su momento. Los que llegaron ofreciendo una nueva (su nueva) visión del mundo. Arribaron sorprendiendo con su forma de hablar y con sus acciones para unificar. Ya lo contó Fray Pedro de Gante en sus "Cartas al Emperador":

\section{(c) (i) (2)}

La Revista Estudios es editada por la Universidad de Costa Rica y se distribuye bajo una Licencia Creative Commons Atribución-NoComercial-CompartirIgual 3.0 Costa Rica. Para más información envíe un mensaje a 
Dossier: La escritura en los desplazamientos: viajes, expediciones y naufragios

"Por ser la esta tierra grandísima, poblada de infinita gente, y los frailes que predican pocos para enseñar a tanta multitud, recogimos en nuestras casas a los hijos de los señores y principales para instruirlos en la fe católica, y que después enseñen a sus padres. Aprendieron estos muchachos a leer, escribir, cantar, predicar y celebrar el oficio divino a uso de iglesia. De ellos tengo a mi cargo en esta ciudad de México al pie de quinientos o más [...] Los domingos salen estos muchachos a predicar por la ciudad y toda su comarca, a cuatro, a ocho o diez, a veinte o treinta leguas, anunciando la fe católica, y preparando con su doctrina a la gente para recibir el bautismo. Nosotros con ellos vamos a la redonda destruyendo ídolos y templos por una parte, mientras ellos hacen lo mismo en otra, y levantamos iglesias al Dios verdadero. Así y en tal ocupación empleamos nuestro tiempo, pasando de toda manera de trabajos de día y de noche, para que este pueblo infiel venga al conocimiento de la fe de Jesucristo."

Considero que casi nunca es suficiente la manera de comprender la complejidad de procesos que se llevan a cabo en los diversos encuentros culturales, así como las negociaciones de identidades (o alteridades) de dos visiones de mundo, en el ambiente de sociedades caracterizadas por la globalización y la particularización dentro de la época en la que actualmente vivimos.

Alcanzo a percibir que es importante considerar la heterogeneidad frente a procesos de homogenización, una lucha por la individualidad en contra de tendencias hegemónicas, globalizadoras como las que nos siguen avasallando.

La pretensión es sencilla en las palabras, compleja en la acción (sobre todo en la acción escénica) sin embargo, el ímpetu e interés se los comparto: habrá que ir a la búsqueda de aspectos discursivos de la identidad, alteridad y la transculturalidad entre nuestros quehaceres. Yo deseo hacer lo propio en lo que al teatro respecta. El hecho escénico, el teatro en su conjunto, que sirvió como arma (instrumento) de Conquista y Colonización desde hace casi 500 años. Aquel viaje que juntó a dos mundos.

En el caso específico de México la conquista europea produjo diversos movimientos a partir del fenómeno teatral que sirvió a los españoles como un vehículo de transmisión de ideas, conceptos, valores e inclusive religión. Sin embargo, los indígenas contaban ya con su propio tipo de "teatro", según María Sten (1974, p. 48) en su libro Vida y muerte del teatro náhuatl, considerando los ritos y las fiestas palaciegas como acto performativo. $Y$ este concepto es el que, en un

\footnotetext{
${ }^{1}$ Op. cit.. 110.

\section{(c) (1) 8 (2)}

La Revista Estudios es editada por la Universidad de Costa Rica y se distribuye bajo una Licencia Creative Commons Atribución-NoComercial-CompartirIgual 3.0 Costa Rica. Para más información envíe un mensaje a
} revistaestudios.eeg@ucr.ac.cr. 
Dossier: La escritura en los desplazamientos: viajes, expediciones y naufragios futuro no muy lejano, desearía ampliar a través de estos temas y sensaciones que nos rigen cuando de Conquista y Colonia hablamos en nuestra América.

Con esto, es pertinente traer a el dramaturgo mexicano Víctor Hugo Rascón Banda, en un viaje instantáneo de nueva cuenta por este mundo, quien en su obra de teatro La Malinche, da voz a un personaje que, según cuenta nuestra historia (o la que nos han contado), vivió hace casi 500 años también. Marina y también Malitzin, le decían. Y en uno de sus diálogos nos confiesa:

MALINCHE. - Eran dos lenguas. Eran dos mundos. No. Dos universos. Tan lejanos, tan opuestos, imposibles de unir y hacer uno solo. Y entonces lo decidí. Yo era la lengua, yo era la intérprete. Ser traductora era mi oficio. Me di cuenta de que los que llegaban no se podían entender con los que acá vivían. Los vencedores jamás se entenderían con los vencidos. Tan diferentes eran. Y me di valor. Me atreví. Mentí a unos y a otros. Cambié las palabras. Me propuse convertir en verdad la gran mentira del entendimiento. Una mentira de dos caras. Por eso pudieron convivir sin hacerse la guerra durante todo un año en Tenochtitlan. Yo inventaba una verdad hecha de mentiras cada vez que traducía de ida y de vuelta entre los dos mundos. Una verdad que sólo podía ser verdad para otro mundo, para otro ser que estaba todavía por llegar. Lo intenté. No me arrepiento. Sólo lamento que la ambición de unos y la desesperación de los otros acabara con mi intento. Yo estaba sola entre los dos. Al lado, a la sombra, sin más poder que mi lengua. Despreciada de unos y de otros. Usada. Lo intenté. Juro que lo intenté. ¿Qué es la verdad? ¿Qué es la mentira? Yo sólo quería un ideal. (1998, pp 95-96).

Así, podemos darnos cuenta que a lo largo de los estudios y análisis de nuestra alteridad americana, es posible encontrarnos muchos ejemplos de cómo algunos artistas escénicos han hecho aproximaciones, sobre todo tomando el personaje de la Malinche / la Malitzin / la Marina.

Con lo anterior, en ocasiones se puede considerar que en algunos discursos de la identidad y transculturalidad, así como en la performatividad posmoderna, los gustosos de las palabras como nosotros podemos trabajar con el "sí mágico" que nos regaló hace años el maestro ruso Stanislavsky en la acción dramática teatral y Dostoievsky en la acción dramática de las letras.

\section{(C) $(\Theta \odot \odot$}

La Revista Estudios es editada por la Universidad de Costa Rica y se distribuye bajo una Licencia Creative Commons Atribución-NoComercial-CompartirIgual 3.0 Costa Rica. Para más información envíe un mensaje a 
Dossier: La escritura en los desplazamientos: viajes, expediciones y naufragios

Desde el subtítulo del libro La colonización de lo imaginario, Serge Gruzinki se pronuncia por la continuidad de México, aun cuando afirma la existencia de un México español, que no Nueva España. En un párrafo de la introducción señala:

“¿Cómo construyen y viven los individuos y los grupos su relación con la realidad, en una sociedad sacudida por una dominación exterior sin antecedente alguno? Son preguntas que no podemos dejar de plantearnos al recorrer el prodigioso terreno que constituye el México conquistado y dominado por los españoles de los siglos XVI al XVIII" (1991, p. 151)

Volviendo a nuestro anfitrión de este congreso, el aventurero y coleccionista Humboldt, este mismo menciona que desde su regreso de América comenzó a ocuparse de manera intensiva del pasado de las colonias españolas, ya que con su orientación histórica partía de la opinión de que hay que conocer el pasado de una región para comprender su presente. Lo hizo, sobre todo, a través de la lectura de las antiguas fuentes españolas, es decir, de los relatos de los primeros cronistas, misioneros, viajeros y funcionarios; y de las recopilaciones e interpretaciones de aquellos escritos a lo que se dedicaron los investigadores en los siglos XVII y XVIII.

El constante movimiento y transformación del viajero y de los objetos, así como del saber sobre éstos constituyen para todas las áreas, inclusive científicas y artísticas como se ha demostrado con este explorador alemán, una manera de seguir viajando en el tren o barco de la nostalgia, hasta el carro o avión de lo efímero del movimiento de la palabra.

"Si América Latina y México quieren un futuro diferente, tendrán que construir, entre otras miles de cosas, un discurso histórico-cultural diferente de su pasado, en el cual todos sus habitantes puedan reconocerse e identificarse de manera enriquecedora" (Rozat, 1992, p. VI)

Para concluir, dejo aquí, en el tiempo y en espacio, estas palabras que todos han leído y comenzado su viaje hacia el inmediato imaginario de nuestras posibles "identidades" o "alteridades" que aún faltan por descubrir a través de nuestros viajes (físicos y en las palabras).

Las alteridades que se trasladarán a distintos escenarios. Encapsuladas en medio de nuestra lengua metida en una botella tirada al mar con la mira puesta a

\section{(@) $\odot \odot$}

La Revista Estudios es editada por la Universidad de Costa Rica y se distribuye bajo una Licencia Creative Commons Atribución-NoComercial-CompartirIgual 3.0 Costa Rica. Para más información envíe un mensaje a 
Dossier: La escritura en los desplazamientos: viajes, expediciones y naufragios nuestras aspiraciones tan potentes y retadoras, aquellas que están encerradas entre lo inter y entre lo multidisciplinario de las letras, del idioma, del México, del drama, del origen, de las Américas.

\section{CONFERENCIA \\ Universidad de Costa Rica \\ Recinto de Golfito \\ 24 de octubre 2019}

Deseo agradecer sinceramente al Dr. Leonardo Sancho Robles y a todo su equipo que lo acompaña en la organización de este encuentro, así como el Recinto del Golfito por la magnífica oportunidad de compartir y explorar nuevos viajes, nuevas palabras y nuevos puertos para cada uno de los que tenemos la fortuna de estar aquí reunidos.

\section{Bibliografía}

Fuentes, C. (1970). Todos los gatos son pardos. España: Siglo XXI Editores.

Gruzinski, S. (1991). La colonización de lo imaginario: Sociedades indígenas y occidentalización en el México español, siglos XVI-XVIII. México: Fondo de Cultura Económica.

Humboldt, A. (1874). COSMOS. Ensayo de una descripción física del mundo. Madrid: Imprenta de Gaspar y Roig Editores.

Rascón Banda, V.H (1998). La Malinche. México: Son de Teatro, Plaza Janés.

Rozat Dupeyron, G. (1992). Indios imaginarios e indios reales: en los relatos de la Conquista de México. México: Tava Editorial

Rozat Dupeyron, G. (2013). Repensar la Conquista. Tomo I Reflexión epistemológica sobre un momento fundador. México: Universidad Veracruzana.

Sten, M. (1974). Vida y muerte del teatro náhuatl. México: Secretaría de Educación Pública.

\section{(C) $(00$}

La Revista Estudios es editada por la Universidad de Costa Rica y se distribuye bajo una Licencia Creative Commons Atribución-NoComercial-CompartirIgual 3.0 Costa Rica. Para más información envíe un mensaje a 
Revista Estudios, (40), 2020.

Junio 2020-Noviembre 2020

ISSN 1659-3316

Dossier: La escritura en los desplazamientos: viajes, expediciones y naufragios

Portilla, L. (Coordinador) (2013). Historia documental de México 1. México: Instituto de Investigaciones Históricas, UNAM.

Portilla, L. (1959) La visión de los vencidos. Relaciones indígenas de la Conquista. México, UNAM.

Williams, M. J. (1993). El Teatro del México Colonial (Época misionera). Estados Unidos: Ibérica.

La Revista Estudios es editada por la Universidad de Costa Rica y se distribuye bajo una Licencia Creative Commons Atribución-NoComercial-CompartirIgual 3.0 Costa Rica. Para más información envíe un mensaje a revistaestudios.eeg@ucr.ac.cr. 